\title{
Accuracy of the European Thyroid Imaging Reporting and Data System (EU-TIRADS) in the valuation of thyroid nodule malignancy in reference to the post-surgery histological results
}

\author{
Anna Skowrońska ${ }^{1 * A, B, C, D, E, F}$, Justyna Milczarek-Banach ${ }^{1 * 0, E, F}$, Wiesław Wiechno ${ }^{2 A, B}$, Witold Chudziński2 ${ }^{2 A, B}$, \\ Marcin Żach ${ }^{1 A, B, D}$, Michał Mazurkiewicz ${ }^{3 A, B}$, Piotr Miśkiewicz ${ }^{1 D, E, F}$, Tomasz Bednarczuk ${ }^{1 A, D}$ \\ 'Department of Internal Medicine and Endocrinology, Medical University of Warsaw, Poland \\ 2Department of General and Endocrine Surgery, Medical University of Warsaw, Poland \\ ${ }^{3}$ Department of Pathology, Medical University of Warsaw, Poland \\ * These authors contributed equally to this work.
}

\section{Abstract}

Purpose: To assess the clinical usefulness of the European Thyroid Imaging and Reporting Data System (EU-TIRADS) in the valuation of thyroid nodules malignancy in reference to post-surgery histological results.

\begin{abstract}
Material and methods: Pre-operative ultrasound was performed in consecutive patients admitted for thyroid surgery between June 2017 and January 2018. Thyroid nodules were classified according to EU-TIRADS to five groups: 1-5. At least one fine-needle aspiration biopsy (FNAB)/patient (dominant or suspected nodule) was performed in an outpatient clinic. The final diagnosis was based on the histological result. The percentage of cancers in each EU-TIRADS group was evaluated. Finally, sensitivity, specificity, accuracy, as well as positive and negative predictive values for malignancy were assessed.
\end{abstract}

Results: Fifty-two patients with a total of 140 thyroid nodules (median: 3 nodules/thyroid [minimum-maximum: 1-6]) were enrolled in the study. Thyroid cancer was diagnosed in 0\% (0/6) in EU-TIRADS 2; 0\% (0/92) in EU-TIRADS 3; $5.9 \%(2 / 34)$ in EU-TIRADS 4, and 75\% (6/8) in EU-TIRADS 5. In nodules assessed as EU-TIRADS $\geq 4$ sensitivity, specificity, positive and negative predictive values for malignancy were, respectively: 75\% (CI 95\%: 40.7-93.5), 94.1\% (CI 95\%: 86.0-98.5), 75\% (CI 95\%: 40.7-93.5), and 94.1\% (CI 95\%: 86.0-98.5).

Conclusions: EU-TIRADS is a valuable and simple tool for assessment of the risk of malignancy of thyroid nodules and demonstrates a high ultrasound correlation with histological post-surgery results. FNAB should be performed in all nodules assessed as EU-TIRADS $\geq 4$, due to higher risk of malignancy.

Key words: EU-TIRADS, risk stratification, thyroid cancer, thyroid nodule, ultrasound, fine-needle aspiration biopsy.

\section{Introduction}

The widespread use of imaging techniques has generated increasing detection rates of thyroid nodules. The prevalence of thyroid nodules is still high and ranges from $50 \%$ to $60 \%$ in healthy people [1]. Ultrasound (US) is currently the best detection tool of choice available for the initial work-up of thyroid nodules. The main aim of thyroid US examination is to distinguish benign nodules from those suspicious for malignant features and requiring further investigation. Approximately $90 \%$ of thyroid lesions are benign, and $95 \%$ are asymptomatic during recognition and further follow-up [2]. Fine-needle aspiration biopsy (FNAB) is used to differentiate between nodules that re-

Correspondence address:

Dr. Piotr Miśkiewicz, Department of Internal Medicine and Endocrinology, Medical University of Warsaw, Poland, e-mail: piotr.miskiewicz@wum.edu.pl

Authors' contribution:

A Study design · B Data collection · C Statistical analysis · D Data interpretation - E Manuscript preparation · F Literature search · G Funds collection 
quire surgery and those that can be followed-up. Approximately $10-20 \%$ of FNAB are non-diagnostic and need to be repeated [3]. The limitations of FNAB include indeterminate or follicular lesions. The prevalence of unnecessary thyroid surgery is still a therapeutic problem [4]. For all these reasons there was a need to establish some basic criteria to select nodules for FNAB to minimise costs and maximise benefits.

US uses a wide range of features that present different sensitivity and specificity in prediction of thyroid cancer. However, none of them could be used alone in detecting or rejecting malignancy efficiently. The main disadvantage of US examination is relatively low specificity and substantial inter-operator variability $[5,6]$. To minimise the impact of these limitations, attempts are being made to develop and refine a standardised system.

The American Association of Clinical Endocrinologists and American Thyroid Association have created a practical clinical statement, for better communication between ultrasound practitioners and clinicians, called Thyroid Imaging, Reporting, and Data System (TIRADS) classification. It was first introduced by Horvath et al. [7], originating from the Breast Imaging Reporting and Data System [8]. Since its introduction, several versions of TIRADS have been endorsed by international medical societies to estimate the final assessment and management of thyroid lesions. All of them classify nodules based on suspicious ultrasound features related to composition, echogenicity, shape, margin, and echogenic foci.

In 2017 the European Thyroid Association developed a new and simple European Thyroid Imaging and Reporting Data System (EU-TIRADS), which classifies the risk of malignancy of thyroid nodules in adults to the following categories: benign, low-, intermediate-, and high-risk (e.g. EU-TIRADS 1 is a normal exam, EU-TIRADS 5 means high risk of malignancy) [9]. The aim of this study was to assess the clinical usefulness of EU-TIRADS in the valuation of thyroid nodule malignancy in reference to post-surgery histological results.

\section{Material and methods}

\section{Patients}

This prospective study was conducted at an academic referral centre between 06.2017 and 01.2018. Patients were admitted to the Department of General and Endocrine Surgery for thyroid or parathyroid surgery. The decision about surgical treatment was made before admission to the hospital, based on clinical, US, laboratory, and FNAB evaluation. Patients were consecutively recruited to the study if they fulfilled the following criteria: 1) preoperative US reassessment of the neck performed by two certified ultrasonographers; 2) preoperative FNAB of dominant or suspicious lesion; 3) surgical thyroid resection with histological evaluation.
All the procedures were performed in accordance with the Helsinki Declaration of 1975, as revised in 2000, and with the ethical standards of the local Research Ethics Committee.

\section{Ultrasound examination}

All patients were reassessed with a preoperative US of the neck for nodal staging by two certified ultrasonographers (AS and MŻ) (certificate of Polish Ultrasound Society) with two and 15 years of experience, respectively, in thyroid US. US was performed in the Department of Endocrinology a few days before the thyroid surgery. All the US scans were performed using a Hitachi Avius Medical ultrasound technique system equipped with a 7.5-12 MHz high-frequency linear array transducer. Thyroid US procedures were performed on the basis of the Ultrasound Examination Standards of the Polish Ultrasound Society (2014) [10]. The neck was scanned in sagittal, transverse, and oblique sections to optimally visualise both lobes of thyroid, isthmus, and carotid arteries, as well as internal jugular veins. All images were examined on real-time two-dimensional B-mode grey-scale and Doppler imaging. All obtained sonograms were saved in a picture archiving and communication system. The US examination study did not change the management of surgical interventions. The interobserver agreement was measured using a weighted kappa statistic with $95 \%$ confidence intervals (CI 95\%). Levels of agreement included values: $\leq 0$ as no agreement, $0.01-0.20$ as slight, $0.21-0.40$ as fair, 0.41 0.60 as moderate, $0.61-0.80$ as substantial, and $0.81-1.00$ as almost perfect agreement. In this study the interobserver agreement was almost perfect.

\section{EU-TIRADS}

According to the EU-TIRADS, we assessed the presence of five equally-weighted nodule features (irregular/non-oval shape, irregular margins, microcalcifications, marked hypoechogenicity, solid component), and assigned the lesion to one of five categories based on the number of suspicious features. To define and specify each US pattern, the following variables were considered: composition (solid, predominantly solid, predominantly cystic, simple cyst, spongiform), echogenicity (hyperechoic, isoechoic, hypoechoic, markedly hypoechoic), margins (circumscribed, non-circumscribed), and calcifications (absent, microscopic, macroscopic - the latter including eggshell calcifications). Other parameters were also recorded: 1) nodule diameters (transverse, anteroposterior, and longitudinal); and 2) nodule shape (oval [wider than tall], non-oval [taller than wide], irregular).

Cervical lymph nodes were evaluated for their size, loss of the central, echogenic hilum, the presence of irregular and indistinct margin, microcalcifications, and necrotic changes.

Normal thyroid gland was classified as EU-TIRADS 1, a benign nodule as EU-TIRADS 2 (Figure 1A,B), a nod- 

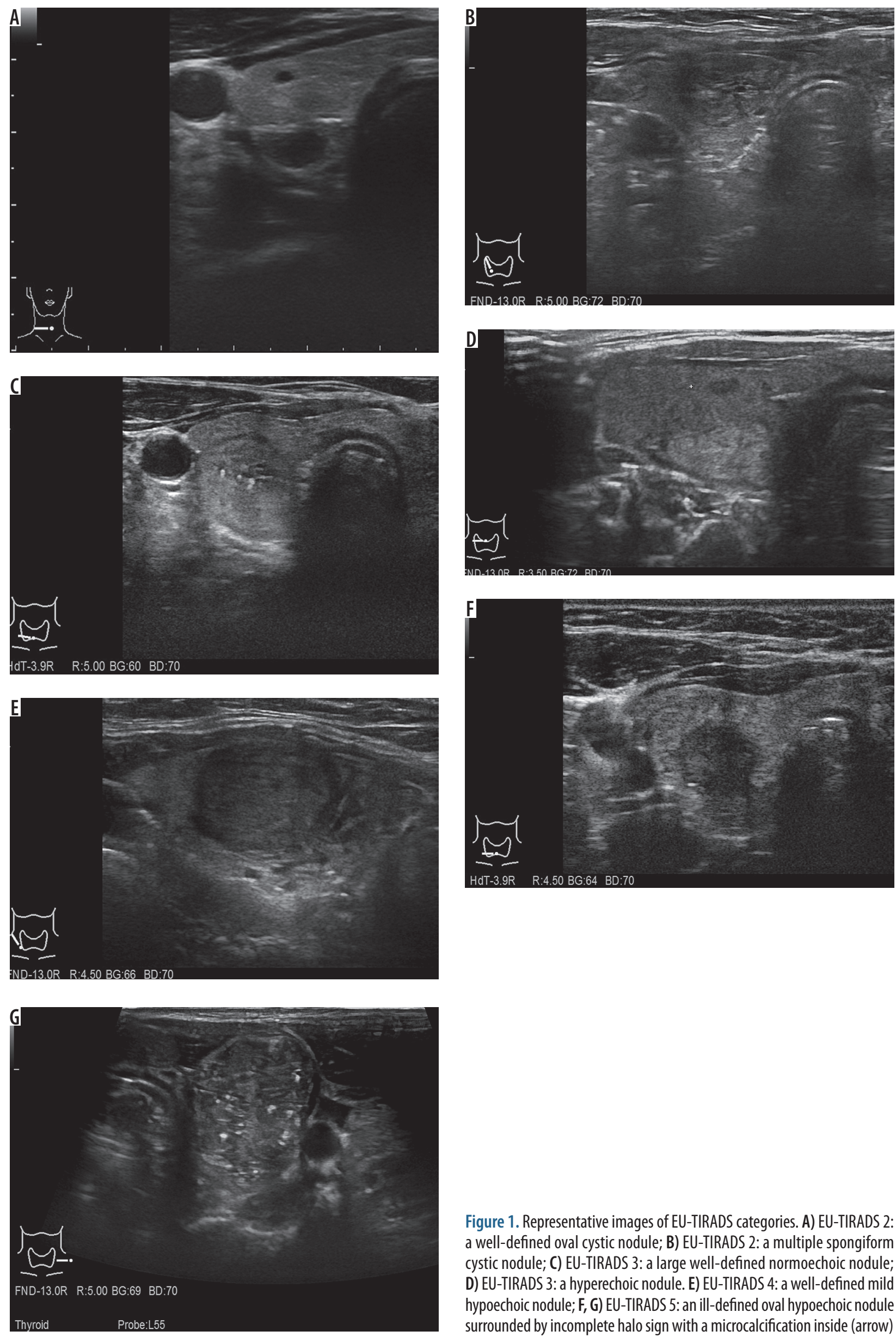

Figure 1. Representative images of EU-TIRADS categories. A) EU-TIRADS 2: a well-defined oval cystic nodule; B) EU-TIRADS 2: a multiple spongiform cystic nodule; C) EU-TIRADS 3: a large well-defined normoechoic nodule; D) EU-TIRADS 3: a hyperechoic nodule. E) EU-TIRADS 4: a well-defined mild hypoechoic nodule; F, G) EU-TIRADS 5: an ill-defined oval hypoechoic nodule surrounded by incomplete halo sign with a microcalcification inside (arrow) 
ule with low suspicion for malignancy as EU-TIRADS 3 (Figure 1C,D), a nodule with intermediate suspicion for malignancy as EU-TIRADS 4 (Figure 1E), and a nodule highly suggestive of malignancy as EU-TIRADS 5 (Figure $1 F, G)$.

\section{Fine-needle aspiration biopsy}

FNAB of dominant or suspicious lesions in US (at least in one thyroid lesion) was performed before the admission to the hospital. The majority of FNABs were completed in the outpatient clinic before admission to the hospital. The Bethesda System for reporting thyroid cytopathology was used in the classification of cytology reports.

\section{Surgery}

Thyroid surgeries were performed in the Department of General and Endocrine Surgery. Total thyroidectomy was performed in 40 patients (eight with suspicion of carcinoma in FNAB, 32 with multinodular goitre), lobectomy in nine $(17.3 \%)$ patients, and lobectomy plus isthmectomy in three (5.8\%) patients. Total thyroidectomy with neck exploration was done in seven (13.5\%) patients, of these lymph nodule dissection was performed in three patients.

\section{Histological evaluation}

Histological evaluation was performed by one pathologist (MM). All of the nodules analysed in US were separately assessed in histological examination.

\section{Statistical analysis}

Statistical analysis was performed using the statistical program STATISTICA 10 (StatSoft Inc.). Qualitative characteristics were described along with their percentage distributions. For quantitative variables, averages and standard deviation (SD) or median (range) were used. The consensus decisions were compared with surgical histology reports (reference standard). Specificity, sensitivity, positive predictive value (PPV), and negative predictive value (NPV) (with 95\% confidence interval [CI 95\%]) were calculated to evaluate the reliability of EU-TIRADS classification in differentiation between benign and malignant features.

\section{Results}

Fifty-two patients ( 44 female) with mean age of $55 \pm 14$ years were enrolled in the study. Patient characteristics including age, sex, indications for surgery, clinical symptoms, thyrotropin, and free thyroid hormone levels are presented in Table 1.

\section{Ultrasound evaluation}

The total amount of thyroid nodules found in US was 140 (median: 3 nodules/patient [minimum-maximum: 1-6]). The details of US examination are shown in Table 2.

\section{EU-TIRADS}

The overall distribution in EU-TIRADS categories was as follows: six EU-TIRADS 2 (4.3\%), 92 EU-TIRADS 3 (65.7\%), 34 EU-TIRADS 4 (24.3\%), and eight EU-TIRADS 5 (5.7\%) (Table 3).

\section{Fine-needle aspiration biopsy}

FNAB of 63 nodules was performed (details in Table 3 ). Among the examined nodules, 37 (58.7\%) were assessed as benign, four (6.3\%) were suspected for malignancy, and two $(3.2 \%)$ were reported as malignant. The rest of them $(20[31.7 \%])$ were categorised as III or IV according to the Bethesda system. In the final histological examination, thyroid cancer was not recognised in nodules with category III in FNAB evaluation, in two among six nodules with category IV (anaplastic and follicular cancer), and in all nodules with category $\mathrm{V}$ (medullary and papillary cancer) and with category VI (lymphoma, anaplastic cancer).

\section{Histological evaluation}

Histological examination revealed 132 (94.3\%) benign nodules (adenomas, hyperplastic, cystic, and colloid nodules) and eight (5.7\%) cancers (details in Table 4).

\section{Comparison of ultrasound and histological evaluation}

The US evaluation of selected patterns of thyroid nodules with comparison between histologically recognised malignant and benign nodules is summarised in Table 2 . Solid composition, hypoechogenicity, microcalcifications, "taller than wide", irregular shape, and non-circumscribed margins were more frequent ultrasound features in malignant lesions than in benign nodules. Similarly, predominantly cystic component, simple cyst, spongiform, hyper-/ isoechogenic, oval, and with circumscribed margins nodules were associated more often with the histological diagnosis of benign lesions. There was no significant difference between the size of benign $(16 \pm 17.5 \mathrm{~mm})$ and malignant nodules $(17.5 \pm 6.8 \mathrm{~mm})$.

\section{Comparison of EU-TIRADS and histological evaluation}

The percentage of malignancy for each EU-TIRADS category was as follows: $0 \%(0 / 6)$ in EU-TIRADS 2; 0\% (0/92) in EU-TIRADS 3; 5.9\% (2/34) in EU-TIRADS 4; and 75\% 
Table 1. Demographic and clinical profile of patients

\begin{tabular}{|c|c|c|c|}
\hline Factor & $\begin{array}{l}\text { All patients } \\
(n=52)\end{array}$ & $\begin{array}{l}\text { Patients with benign } \\
\text { nodules }(n=44)\end{array}$ & $\begin{array}{l}\text { Patients with malignant } \\
\text { nodules }(n=8)\end{array}$ \\
\hline \multicolumn{4}{|l|}{ Age (years) } \\
\hline Mean & $55 \pm 14$ & $56 \pm 12$ & $35 \pm 16$ \\
\hline$<30$ & $3(5.8 \%)$ & $1(2.3 \%)$ & $2(25 \%)$ \\
\hline $30-39$ & $9(17.3 \%)$ & $7(15.9 \%)$ & $2(25 \%)$ \\
\hline $40-49$ & $9(17.3 \%)$ & $9(20.5 \%)$ & - \\
\hline $50-59$ & $10(19.2 \%)$ & $9(20.5 \%)$ & $1(12.5 \%)$ \\
\hline $60-69$ & $15(28.8 \%)$ & $14(31.8 \%)$ & $1(12.5 \%)$ \\
\hline$\geq 70$ & $6(11.5 \%)$ & $4(9.1 \%)$ & $2(25 \%)$ \\
\hline \multicolumn{4}{|l|}{ Sex } \\
\hline Female & $44(84.6 \%)$ & $39(88.6 \%)$ & $5(62.5 \%)$ \\
\hline Male & $8(15.4 \%)$ & $5(11.4 \%)$ & $3(37.5 \%)$ \\
\hline \multicolumn{4}{|l|}{ Clinical symptoms } \\
\hline Goitre compression & $25(48.1 \%)$ & $24(54.5 \%)$ & $1(12.5 \%)$ \\
\hline Laryngeal nerve palsy & $2(3.8 \%)$ & - & $2(25 \%)$ \\
\hline Rapidly enlarging mass & $4(7.7 \%)$ & $2(4.5 \%)$ & $2(25 \%)$ \\
\hline Hyperthyroidism & $5(9.6 \%)$ & $4(9.1 \%)$ & $1(12.5 \%)$ \\
\hline Cervical lymphadenopathy & $2(3.8 \%)$ & - & $2(25 \%)$ \\
\hline \multicolumn{4}{|l|}{ Thyroid function } \\
\hline TSH (0.27-4.2 mlU/I) & $1.33 \pm 0.84$ & $1.31 \pm 0.85$ & $1.44 \pm 0.78$ \\
\hline $\mathrm{FT}_{4}(12-22 \mathrm{pmol} / \mathrm{l})$ & $16.30 \pm 2.45$ & $16.15 \pm 2.43$ & $17.70 \pm 2.21$ \\
\hline $\mathrm{FT}_{3}(3.1-6.8 \mathrm{pmol} / \mathrm{l})$ & $4.84 \pm 0.76$ & $4.84 \pm 0.77$ & $5.25 \pm 0.68$ \\
\hline \multicolumn{4}{|l|}{ Indications for surgery } \\
\hline Suspicion of malignancy & $12(23.1 \%)$ & $6(13.6 \%)$ & $6(75 \%)$ \\
\hline Goitre size and signs of compression & $20(38.5 \%)$ & $19(43.2 \%)$ & $1(12.5 \%)$ \\
\hline Toxic multinodular goitre & $5(9.6 \%)$ & $4(9.1 \%)$ & $1(12.5 \%)^{*}$ \\
\hline Cosmetic problems & $2(3.8 \%)$ & $2(4.5 \%)$ & - \\
\hline \multicolumn{4}{|l|}{ Other } \\
\hline $\begin{array}{l}\text { Multinodular goitre and primary } \\
\text { hyperparathyroidsm }\end{array}$ & $13(25 \%)$ & $13(29.5 \%)$ & - \\
\hline
\end{tabular}

$\mathrm{FT}_{3}$ - free triiodothyronine, $\mathrm{FT}_{4}$ - free thyroxine, $\mathrm{TSH}$ - thyrotropin

* Incidental, histologically detected follicular microcarcinoma

$(6 / 8)$ in EU-TIRADS 5. In nodules assessed as EU-TIRADS $\geq 4$, predictive values for malignancy were assessed: sensitivity of 75\% (CI 95\%: 40.7-93.5); specificity of $94.1 \%$ (CI 95\%: 86.0-98.5); PPV of 75\% (CI 95\%: 40.7-93.5); and NPV of $94.1 \%$ (CI 95\%: 86.0-98.5).

\section{Discussion}

For the last nine years several attempts have been made to create a standardised systematic categorisation of thyroid nodules according to their risk of malignancy, in order to optimise focal lesion management through US follow-up, cytological analysis, and surgical treatment with pathological verification.
In 2009, Horvath et al. and then Park et al. [7,11], first presented the Thyroid Imaging Reporting and Data System (TIRADS). The system, based on 10 US patterns proposed in a prospective study by Horvath et al. did not cover the entire spectrum of lesions that may occur in thyroid nodules, especially multinodular goitre. The classification described in a retrospective study by Park et al., based on a formula for calculation of TIRADS, seemed to be too complicated for common use by US practitioners. In 2011 Kwak et al. [12] published another approach for TIRADS classification, a more accurate tool in daily practice for the evaluation of thyroid cancer in multinodular goitre, particularly to select cases that require biopsy [13]. Russ et al. [14] presented in 2013, in a large prospective 
Table 2. Ultrasound features of benign and malignant nodules

\begin{tabular}{|c|c|c|c|}
\hline Ultrasound features & $\begin{array}{c}\text { All nodules } \\
(n=140,100 \%)\end{array}$ & $\begin{array}{c}\text { Benign nodules } \\
(n=132,94.3 \%)\end{array}$ & $\begin{array}{l}\text { Malignant nodules } \\
\qquad(n=8,5.7 \%)\end{array}$ \\
\hline \multicolumn{4}{|l|}{ Composition } \\
\hline Solid & 41 & $34(25.8 \%)$ & $7(87.5 \%)$ \\
\hline Predominantly solid & 62 & $61(46.2 \%)$ & $1(12.5 \%)$ \\
\hline Predominantly cystic & 30 & $30(22.7 \%)$ & - \\
\hline Simple cyst & 3 & $3(2.3 \%)$ & - \\
\hline Spongiform & 4 & $4(3.1 \%)$ & - \\
\hline \multicolumn{4}{|l|}{ Echogenicity } \\
\hline Hypo-/markedly hypo- & 73 & $65(49.2 \%)$ & $8(100 \%)$ \\
\hline Hyper-/iso- & 67 & $67(50.8 \%)$ & - \\
\hline \multicolumn{4}{|l|}{ Margins } \\
\hline Circumscribed & 134 & $132(100 \%)$ & $2(25 \%)$ \\
\hline Non-circumscribed & 6 & - & $6(75 \%)$ \\
\hline \multicolumn{4}{|l|}{ Calcifications } \\
\hline Microcalcifications & 5 & $2(1.5 \%)$ & $3(37.5 \%)$ \\
\hline Macrocalcifications & 17 & $16(12.1 \%)$ & $1(12.5 \%)$ \\
\hline None & 118 & $114(86.4 \%)$ & $4(50 \%)$ \\
\hline \multicolumn{4}{|l|}{ Shape } \\
\hline Oval (wider than tall) & 134 & $131(99.2 \%)$ & $3(37.5 \%)$ \\
\hline Non-oval (taller than wide & 6 & $1(0.8 \%)$ & $5(62.5 \%)$ \\
\hline Irregular & 8 & - & $8(100 \%)$ \\
\hline \multicolumn{4}{|l|}{ Lymphatic nodes } \\
\hline Suspected for malignancy & 2 & - & $2(25 \%)$ \\
\hline
\end{tabular}

$n$-number of nodules, US - ultrasound

Table 3. The results of EU-TIRADS classification

\begin{tabular}{|c|c|c|c|}
\hline $\begin{array}{l}\text { EU-TIRADS } \\
n(\%)\end{array}$ & $\begin{array}{l}\text { Nodule size (mm), } \\
\text { median (range) }\end{array}$ & $\begin{array}{c}\text { Preoperative FNAB } \\
n(\%)\end{array}$ & $\begin{array}{l}\text { Histopathological findings } \\
\qquad n(\%)\end{array}$ \\
\hline $\begin{array}{l}\text { EU-TIRADS } 2 \\
6(4.3 \%)\end{array}$ & $19.5(6.0-41.0)$ & II $-3(4.8 \%)$ & $\begin{array}{l}\text { Colloid nodule }-3(50 \%) \\
\text { Simple cyst }-3(50 \%)\end{array}$ \\
\hline $\begin{array}{l}\text { EU-TIRADS } 3 \\
92(65.7 \%)\end{array}$ & $18.0(5.0-47.5)$ & $\begin{array}{c}\text { II }-28(44.4 \%) \\
\text { III }-7(11.1 \%) \\
\text { IV }-1(1.6 \%)\end{array}$ & $\begin{array}{l}\text { Colloid nodule }-66(71.7 \%) \\
\text { Hyperplastic nodule }-25(27.2 \%) \\
\text { Adenoma - } 2(2.2 \%)\end{array}$ \\
\hline $\begin{array}{l}\text { EU-TIRADS } 4 \\
34(24.3 \%)\end{array}$ & $11.6(5.0-29.0)$ & $\begin{array}{l}\text { II }-9(14.3 \%) \\
\text { III }-4(6.3 \%) \\
\text { IV }-3(4.8 \%) \\
V-1(1.6 \%) \\
V I-1(1.6 \%)\end{array}$ & $\begin{array}{l}\text { Colloid nodule - } 20 \text { (58.8\%) } \\
\text { Hyperplastic nodule - } 12(35.3 \%) \\
\text { Adenoma - } 2 \text { (5.9\%) } \\
\text { Papillary cancer - } 1(2.9 \%) \\
\text { Anaplastic cancer - } 1(2.9 \%)\end{array}$ \\
\hline $\begin{array}{l}\text { EU-TIRADS } 5 \\
8(24.3 \%)\end{array}$ & $17.8(14.2-34)$ & $\begin{array}{l}\text { IV }-2(3.2 \%) \\
V-3(4.8 \%) \\
V I-1(1.6 \%)\end{array}$ & $\begin{array}{l}\text { Hyperplastic nodule }-2(25 \%)^{*} \\
\text { Lymphoma }-1(12.5 \%) \\
\text { Papillary cancer }-2(25 \%) \\
\text { Follicular cancer }-2(25 \%) \\
\text { Medullary cancer }-1(12.5 \%)\end{array}$ \\
\hline
\end{tabular}


study based on the results of 4550 thyroid nodules, a simple classification that included only five suspicious sonographic patterns, together with optional elastography. In 2017, the American College of Radiology Thyroid Imaging Reporting and Data System (ACR TI-RADS) was published [15]. Unlike other guidelines, the ACR TI-RADS does not recommend FNAB of nodules with benign US characteristics regardless of size. The novel EU-TIRADS classification created recently by the European Thyroid Association assesses the presence of five equally-weighted lesion patterns and assigns the nodule to one of five categories, based on the number of suspicious features. This system is both practical and accurate.

To our knowledge, our study is the first prospective trial that assesses EU-TIRADS classification in the correlation with histological findings received from surgical specimens.

Among nodules evaluated as EU-TIRADS 2 or 3 we did not find any cancer. In nodules assessed as EU-TIRADS 4 and 5 we diagnosed thyroid carcinoma in two (6\%) and six $(75 \%)$ nodules, respectively. These results are in accordance with EU-TIRADS statement: FNAB is not necessary in EU-TIRADS 2, but should be performed in EU-TIRADS 4 and 5. In EU-TIRADS 3 FNAB should be performed only for nodules $>20 \mathrm{~mm}$ [9].

With a cut-off point at EU-TIRADS $\geq 4$, sensitivity, specificity, positive predictive value (PPV), and negative predictive value (NPV) for recognition of nodules malignancy were: $75 \%, 94.1 \%, 75 \%$, and $94.1 \%$, respectively. In the prospective validation of TIRADS classification performed by Horvath et al. [16] in 502 resected thyroid nodules with a cut-off point at TIRADS $\geq 4$ to perform FNAB, the specificity was lower $(74.4 \%)$, but the sensitivity, PPV, and NPV were higher $(99.6 \%, 82.1 \%$, and $99.4 \%$, respectively). According to the results described by Russ et al. [14] for TIRADS grey-scale score in combination with cytological results sensitivity, specificity, and negative predictive value were as follows: $95.7 \%, 61 \%$, and $99.7 \%$, respectively.

Additionally, we found that solid composition, hypoechogenicity, microcalcification, "taller than wide", irregular shape, and non-circumscribed margins were more frequent ultrasound features in malignant lesions. Nodules with predominantly cystic component, simple cyst, spongiform, hyper-/isoechogenic, oval, and with circumscribed margins were associated with the histological diagnosis of benign lesions. This is in accordance with the results of previous studies [17-20].

The limitations of this study include: (i) relative small sample size; (ii) small number of thyroid cancers; and (iii) the lack of US examination with the usage of elastography. It would be interesting to compare the results with those presented by Russ et al. [14], Migda et al. [21], and Dobruch-Sobczak et al. [22]. According to Gietka et al. [23], Wolinski et al. [24], and Zhao et al. [25], realtime elastography, shear wave elastography, and three-
Table 4. Histological evaluation $(n=140)$

\begin{tabular}{|c|c|c|}
\hline $\begin{array}{l}\text { Histological } \\
\text { evaluation }\end{array}$ & $\begin{array}{l}\text { Nodules } \\
n(\%)\end{array}$ & Ultrasonography \\
\hline $\begin{array}{l}\text { Colloid } \\
\text { nodule }\end{array}$ & $89(63.6 \%)$ & $\begin{array}{l}\text { Solid - } 19(21.3 \%) \\
\text { Predominantly solid - } 38 \text { (42.7\%) } \\
\text { Predominantly cystic - } 21(23.6 \%) \\
\text { Simple cyst - 3 (3.4\%) } \\
\text { Spongiform - } 8 \text { (8.9\%) } \\
\text { Hypo-/markedly hypoechoic - } 14(15.7 \%) \\
\text { Hyper-/isoechoic - } 75(84.3 \%)\end{array}$ \\
\hline $\begin{array}{l}\text { Hyperplastic } \\
\text { nodule }\end{array}$ & $39(27.9 \%)$ & $\begin{array}{l}\text { Solid - } 12 \text { (31.6\%) } \\
\text { Predominantly solid - } 19 \text { (48.7\%) } \\
\text { Predominantly cystic - } 8(21.1 \%) \\
\text { Hypo-/markedly hypoechoic - } 6 \text { (15.8\%) } \\
\text { Hyper-/isoechoic - } 32 \text { (8.2\%) }\end{array}$ \\
\hline Adenoma & $4(2.9 \%)$ & $\begin{array}{l}\text { Solid - } 4 \text { (100\%) } \\
\text { Hypo-/markedly hypoechoic - } 4 \text { (100\%) }\end{array}$ \\
\hline $\begin{array}{l}\text { Follicular } \\
\text { cancer }\end{array}$ & $2(1.4 \%)$ & $\begin{array}{l}\text { Solid - } 1(50 \%) \\
\text { Predominantly solid - } 1(50 \%) \\
\text { Hypo-/markedly hypoechoic - } 2(100 \%) \\
\text { Non-circumscribed - } 1(50 \%)\end{array}$ \\
\hline $\begin{array}{l}\text { Papillary } \\
\text { cancer }\end{array}$ & $3(2.1 \%)$ & $\begin{array}{l}\text { Solid - } 3(100 \%) \\
\text { Hypo-/markedly hypoechoic - } 3(100 \%) \\
\text { Non-circumscribed - 3 (100\%) }\end{array}$ \\
\hline $\begin{array}{l}\text { Medullary } \\
\text { cancer }\end{array}$ & $1(0.7 \%)$ & $\begin{array}{l}\text { Solid - } 1 \text { (100\%) } \\
\text { Hypo-/markedly hypoechoic - } 1 \text { (100\%) }\end{array}$ \\
\hline $\begin{array}{l}\text { Anaplastic } \\
\text { cancer }\end{array}$ & $1(0.7 \%)$ & $\begin{array}{l}\text { Solid - } 1(100 \%) \\
\text { Hypo-/markedly hypoechoic - } 1 \text { (100\%) } \\
\text { Non-circumscribed - } 1 \text { (100\%) }\end{array}$ \\
\hline Lymphoma & $1(0.7 \%)$ & $\begin{array}{l}\text { Solid - } 1 \text { (100\%) } \\
\text { Hypo-/markedly hypoechoic - } 1 \text { (100\%) } \\
\text { Non-circumscribed - } 1 \text { (100\%) }\end{array}$ \\
\hline
\end{tabular}

$n$ - number of nodules

dimensional shear wave elastography are useful in selecting nodules to FNAB. However, other authors reported clearly that grey-scale with elastography has poorer results for discriminating benign from malignant thyroid lesions in comparison to single grey-scale assessment [26-28].

\section{Conclusions}

To conclude, EU-TIRADS is a valuable and simple tool in assessing the malignancy of thyroid nodules, which demonstrates a high clinical correlation with histological results. Because of its high sensitivity it can be used in selecting nodules with a high risk of cancer. EU-TIRADS improves qualification for surgical treatment and leads to the avoidance of unnecessary procedures such as FNAB of benign thyroid nodules.

\section{Conflict of interest}

The authors report no conflict of interest. 


\section{References}

1. Gharib H, Papini E, Garber JR, et al. American Association of Clinical Endocrinologists, American College of Endocrinology, and Associazione Medici Endocrinologi Medical Guidelines for Clinical Practice for The Diagnosis and Management of Thyroid Nodules - 2016 Update. Endocr Pract 2016; 22: 622-639.

2. Durante C, Grani G, Lamartina L, et al. The diagnosis and management of thyroid nodules: a review. JAMA 2018; 319: 914-924.

3. Chow LS, Gharib H, Goellner JR, et al. Nondiagnostic thyroid fine-needle aspiration cytology: management dilemmas. Thyroid 2001; 11: $1147-1151$.

4. Jarząb B, Dedecjus M, Słowińska-Klencka D, et al. Guidelines of Polish National Societies Diagnostics and Treatment of Thyroid Carcinoma. 2018 Update. Endokrynol Pol 2018; 69: 34-74.

5. Ko SY, Lee HS, Kim EK, et al. Application of the Thyroid Imaging Reporting and Data System in thyroid ultrasonography interpretation by less experienced physicians. Ultrasonography 2014; 33: 49-57.

6. Lee HJ, Yoon DY, Seo YL, et al. Intraobserver and interobserver variability in ultrasound measurements of thyroid nodules. J Ultrasound Med 2018; 37: 173-178.

7. Horvath E, Majlis S, Rossi R, et al. An ultrasonogram reporting system for thyroid nodules stratifying cancer risk for clinical management. J Clin Endocrinol Metab 2009; 94: 1748-1751.

8. Vanel D. The American College of Radiology (ACR) Breast Imaging and Reporting Data System (BI-RADS): a step towards a universal radiological language? Eur J Radiol 2007; 61: 183.

9. Russ G, Bonnema SJ, Erdogan MF, et al. European Thyroid Association Guidelines for Ultrasound Malignancy Risk Stratification of Thyroid Nodules in Adults: The EU-TIRADS. Eur Thyroid J 2017; 6: 225-237.

10. Trzebińska A, Dobruch-Sobczak K, Jakubowski W, et al. Standards of the Polish Ultrasound Society - update. Ultrasound examination of thyroid gland and ultrasound-guided thyroid biopsy. J Ultrason 2014; 14: 49-60.

11. Park JY, Lee HJ, Jang HW, et al. A proposal for a thyroid imaging reporting and data system for ultrasound features of thyroid carcinoma. Thyroid 2009; 19: 1257-1264.

12. Kwak JY, Han KH, Yoon JH, et al. Thyroid imaging reporting and data system for US features of nodules: a step in establishing better stratification of cancer risk. Radiology 2011; 260: 892-899.

13. Migda B, Migda M, Migda MS, et al. Use of the Kwak Thyroid Image Reporting and Data System (K-TIRADS) in differential diagnosis of thyroid nodules: systematic review and meta-analysis. Eur Radiol 2018; 28: 2380-2388.

14. Russ G, Royer B, Bigorgne C, et al. Prospective evaluation of thyroid imaging reporting and data system on 4550 nodules with and without elastography. Eur J Endocrinol 2013; 168: 649-655.

15. Tessler FN, Middleton WD, Grant EG, et al. ACR Thyroid Imaging, Reporting and Data System (TI-RADS): White Paper of the ACR TI-RADS Committee. J Am Coll Radiol 2017; 14: 587-595
16. Horvath E, Silva CF, Majlis S, et al. Prospective validation of the ultrasound based TIRADS (Thyroid Imaging Reporting And Data System) classification: results in surgically resected thyroid nodules. Eur Radiol 2017; 27: 2619-2628.

17. Brito JP, Gionfriddo MR, Al Nofal A, et al. The accuracy of thyroid nodule ultrasound to predict thyroid cancer: systematic review and meta-analysis. J Clin Endocrinol Metab 2014; 99: 1253-1263.

18. Remonti LR, Kramer CK, Leitão CB, et al. Thyroid ultrasound features and risk of carcinoma: a systematic review and meta-analysis of observational studies. Thyroid 2015; 25: 538-550.

19. Campanella P, Ianni F, Rota CA, et al. Quantification of cancer risk of each clinical and ultrasonographic suspicious feature of thyroid nodules: a systematic review and meta-analysis. Eur J Endocrinol 2014; 170: R203-211.

20. Whittle C, García M, Horvath E, et al. Thyroid microcalcifications in the absence of identifiable nodules and their association with thyroid cancer. J Ultrasound Med 2018; 38: 97-102.

21. Migda B, Migda M, Migda AM, et al. Evaluation of Four Variants of the Thyroid Imaging Reporting and Data System (TIRADS) Classification in Patients with Multinodular Goiter - initial study. Endokrynol Pol 2018; 69: 156-162.

22. Dobruch-Sobczak K, Zalewska EB, Gumińska A, et al. Diagnostic performance of shear wave elastography parameters alone and in combination with conventional b-mode ultrasound parameters for the characterization of thyroid nodules: a prospective, dual-center study. Ultrasound Med Biol 2016; 42: 2803-2811.

23. Gietka-Czernel M, Kochman M, Bujalska K, et al. Real-time ultrasound elastography - a new tool for diagnosing thyroid nodules. Endokrynol Pol 2010; 61: 652-657.

24. Woliński K, Szczepanek-Parulska E, Stangierski A, et al. How to select nodules for fine-needle aspiration biopsy in multinodular goitre. Role of conventional ultrasonography and shear wave elastography - a preliminary study. Endokrynol Pol 2014; 65: 114-118.

25. Zhao CK, Chen SG, Alizad A, et al. Three-dimensional shear wave elastography for differentiating benign from malignant thyroid nodules. J Ultrasound Med 2018; 37: 1777-1788.

26. Moon HJ, Sung JM, Kim EK, et al. Diagnostic performance of grayscale US and elastography in solid thyroid nodules. Radiology 2012; 262: 1002-1013.

27. Bojunga J, Herrmann E, Meyer G, et al. Real-time elastography for the differentiation of benign and malignant thyroid nodules: a meta-analysis. Thyroid 2010; 20: 1145-1150.

28. Cantisani V, D’Andrea V, Biancari F, et al. Prospective evaluation of multiparametric ultrasound and quantitative elastosonography in the differential diagnosis of benign and malignant thyroid nodules: preliminary experience. Eur J Radiol 2012; 81: 2678-2683. 